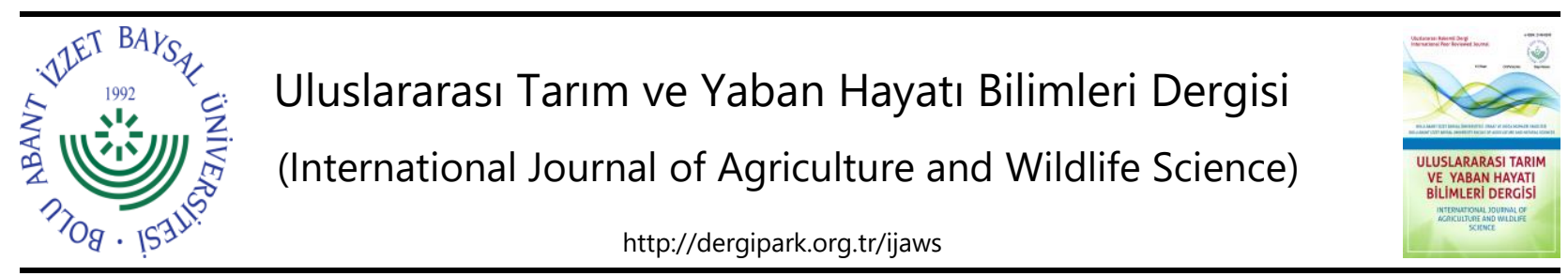

Araştırma Makalesi

\title{
Bazı Ekonomik Toprak Nem Sensörlerinin Hassasiyetlerinin Belirlenmesi
}

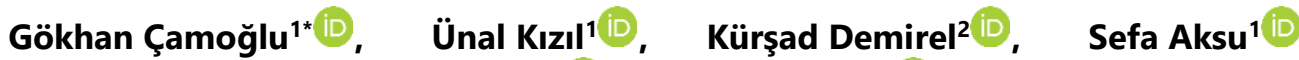 \\ Hakan Nar ${ }^{1}$ i , Levent Genç ${ }^{3}$ (i) \\ ${ }^{1}$ Çanakkale Onsekiz Mart Üniversitesi, Ziraat Fakültesi, Tarımsal Yapılar ve Sulama Bölümü, Çanakkale \\ ${ }^{2}$ Çanakkale Onsekiz Mart Üniversitesi, Mimarlık ve Tasarım Fakültesi, Peyzaj Mimarlığı Bölümü, Çanakkale \\ ${ }^{3}$ Çanakkale Onsekiz Mart Üniversitesi, Mimarlık ve Tasarım Fakültesi, Şehir ve Bölge Planlama Bölümü, Çanakkale
}

Geliş tarihi (Received): 25.12.2020Ｋabul tarihi (Accepted): 13.04.2021

\begin{abstract}
Anahtar kelimeler:
Toprak nem sensörü, toprak nemi, Decagon, gravity analog sensör, kapasitif sensör

Özet. Son yıllarda ucuzlayan bazı toprak nem sensörlerinin kullanımı Arduino mikroişlemci kontrol kartları sayesinde giderek artmaktadır. Buradan hareketle çalışma kapsamında, oldukça ekonomik olan 3 farklı toprak nem sensörünün son yıllarda sıklıkla kullanılan Arduino mikroişlemci kontrol kartıyla toprak nemini belirlemede kullanılabilirliği araştırılmıştır. Bu amaçla yapılan çalışmada 4 farklı tipte sensör ele alınmıştır. Bu sensörlerden biri kontrol sensörü (10HS, DECAGON) olarak kullanılmış, diğerleri de Arduino toprak nem sensörü, gravity analog toprak nem sensörü ve kapasitif toprak nem sensörü olarak bilinen ve sıklıkla kullanılan sensörlerden seçilmiştir. Bu sensörlerin, topraklı (orta bünye) ve topraksız ( $1 / 1$ oranında torf+perlit) olmak üzere iki farklı yetiştirme ortamında toprak nemine karşı tepkileri belirlenmiştir. Araştırma kapsamında elde edilen sonuçlara göre performansı test edilen 3 farklı toprak nem sensörünün özellikle topraksız ortamda doğru okuma yapamadığı tespit edilmiştir. Ayrıca toprak nemini algılama konusunda da çok değişken sonuçlar elde edilmiştir. Oksitlenmeden dolayı ekonomik ömürlerinin çok kısa olduğu anlaşılmıştır. Elde edilen sonuçlara göre bu nem sensörlerinin kullanımı konusunda dikkatli olunması gerektiği söylenebilir.
\end{abstract}

\section{Determination of the Sensitivity of Some Economical Soil Moisture Sensors}

\section{Keywords:}

Soil moisture sensor, soil moisture, Decagon, gravity analog sensor, capacitive sensor

\begin{abstract}
The use of some soil moisture sensors, which have been getting cheaper in recent years, has been increasing thanks to Arduino microprocessor control cards. Within the scope of this study, the usability of economical 3 different soil moisture sensors in determining soil moisture with the Arduino microprocessor control card, which has been used frequently in recent years, has been investigated. For this purpose, 4 different types of sensors were tested in the study. One of these sensors has been used as a control sensor (10HS, DECAGON), while others consist of commonly used sensors known as the Arduino soil moisture sensor, gravity analog soil moisture sensor and capacitive soil moisture sensor. The responses of these sensors to soil moisture were determined in two different growing mediums: soil (medium body) and soilless (peat + perlite). According to the results obtained in the research, it was determined that 3 different soil moisture sensors whose performance was tested could not read correctly in the peat+perlite medium. In addition, the results obtained regarding the detection of soil moisture were varying in a wide range. It is understood that their economic life is very short due to rapid oxidation. Care should be taken in the use of these moisture sensors according to the results obtained.
\end{abstract}




\section{GíRiş}

Günümüzde su kaynaklarının yetersiz oluşu sulama suyunun daha etkili kullanımını zorunlu hale getirmiştir. Tarımsal amaçlı üretimde, nitelikli ve bol ürün alınabilmesi için bitkilerin yetişme koşullarını etkileyen faktörlerin ortaya konulması gerekmektedir. Toprak nemi bu faktörlerin en başında gelmektedir (Demirel, 2012). Toprak nemi, ürünlerin büyümesine ve verimliliğine etki eden önemli bir faktördür.

Toprak nem içeriği doğrudan ölçülebildiği gibi, dolaylı olarak gelişen teknolojilere bağlı çok farklı yöntem ve aygıtlarla da belirlenebilmektedir. Toprak neminin doğrudan ölçümü hem zaman hem de işgücü nedeniyle çoğu zaman pratik olmamaktadır. Bu nedenle, toprak nemini dolaylı ölçebilen farklı yöntem ve aygıtlar, topraktaki nemi yüksek doğrulukta ve hızlı bir şekilde belirleyebilmektedir (Çetin, 2003). Toprak nem içeriği gravimetrik yöntemin yanı sıra nötronmetre, tansiyometre ve elektriksel direnç blokları yöntemleri ile belirlenebilir. Ancak böyle yöntemler ile anlık ve sürekli olarak nemin izlenmesi mümkün olmamaktadır. Günümüzde bunların dezavantajlarını ortadan kaldıran toprak nem sensörlerinin kullanımı artmıştır. Bu sensörler, nötronmetredeki gibi radyoaktif ölçüm yapmaması, toprağın üst kısımlarında da ölçüm yapabilmesi, nemi sürekli ve anlık olarak izlemeye olanak sağlaması nedeniyle otomasyona uygun olması, toprak içerisine yerleştirildikten sonra uzun bir süre ölçüm yapmaya imkan sağlaması, maliyetlerinin daha uygun hale gelmesi, toprağın eşik değerleri içerisinde nem değerinin tutulmasına olanak sağlaması gibi avantajları bulunmaktadır (Topp, 2003; Cardenas-Lailhacar ve Dukes, 2010; Demirel, 2012).

Günümüze kadar sensörler ile ilgili çok sayıda çalışma yapılmıştır (Starr ve Paltineanu, 1998; Heng ve ark., 2002; Leib ve ark., 2003; Huang ve ark., 2004; Paige ve Timothy, 2008; Chow ve ark., 2009; Cardenas-Lailhacar ve Dukes, 2010). Ancak bu çalışmalarda kullanılan sensörlerin maliyetinin yüksek olması kullanımını kısıtlayan en önemli unsurdur. Bununla birlikte son yıllarda piyasada ticari olarak satış olanağı bulunan daha basit ve ucuz sensörler geliştirilmiştir. Ancak oldukça düşük maliyete sahip bu sensörlerin uzun süreli kullanımda güvenilirliği, toprak nemine karşı tepkisi ve sulama uygulamalarında randımanlı kullanılıp kullanılamayacağı yeterince araştırılmamıştır. Bu nedenle, bu çalışmanın amacı, maliyeti düşük ve Arduino ile kullanım olanağı bulunan farklı tipteki toprak nem sensörlerinin farklı yetiştirme ortamlarında toprak neminin izlenmesinde kullanım olanaklarını araştırmaktır.

\section{MATERYAL VE METOT}

\section{Deneme Düzeni}

Deneme, Çanakkale Onsekiz Mart Üniversitesi Ziraat Fakültesi Tarımsal Yapılar ve Sulama Bölümü, Tarımsal Sensör ve Uzaktan Algılama Laboratuvarı'nda yürütülmüştür. Yetiştirme ortamlarının, toprak tekstürü ve hacim ağırlığı gibi değerleri Çanakkale Onsekiz Mart Üniversitesi, Ziraat Fakültesi, Tarımsal Yapılar ve Sulama Bölümü'ne ait laboratuvarda belirlenmiştir.

Denemede biri kontrol olmak üzere toplam 4 farklı tipte toprak nem sensörü iki farklı yetiştirme ortamında kullanılmıştır (Şekil 1).
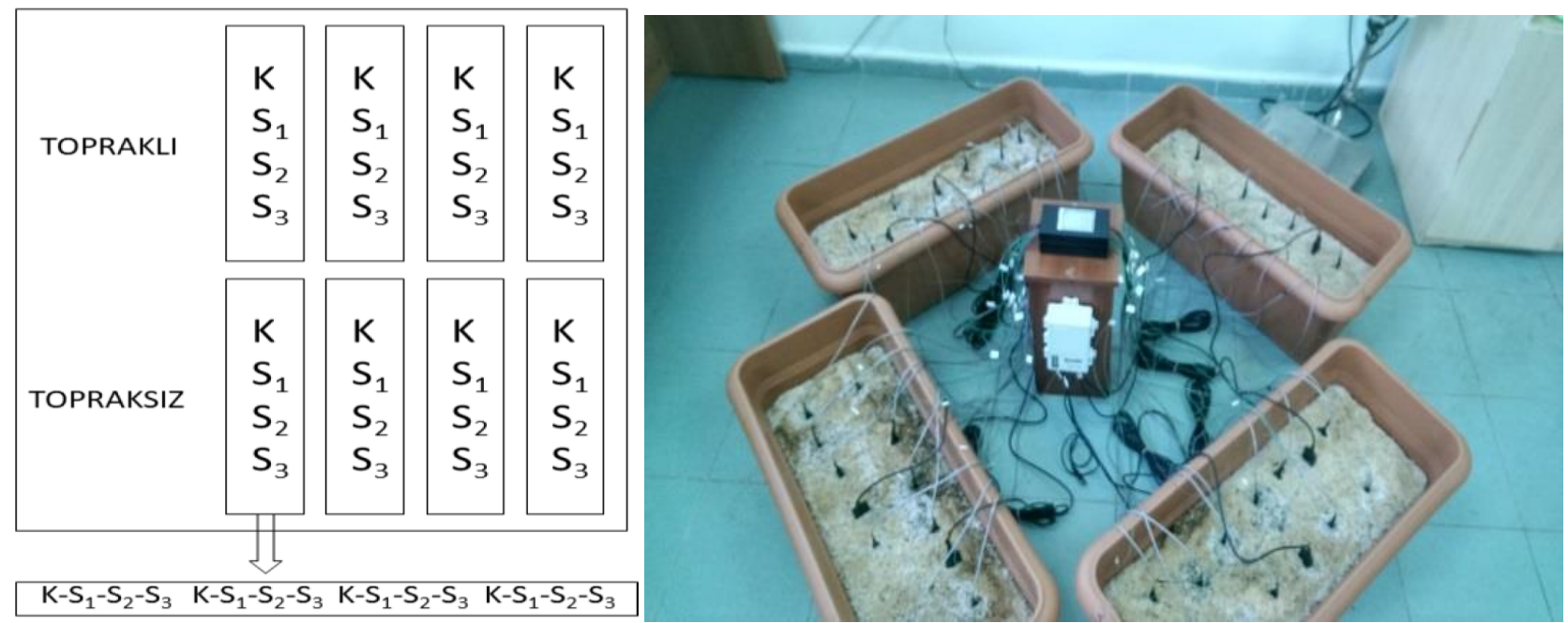

Şekil 1. Deneme düzeni.

Figure 1. Experimental design.

Yetiştirme ortamı olarak orta bünyeye sahip toprak ile $1 / 1$ oranında torf ve perlit karışımı kullanılmıştır. Deneme, her bir yetiştirme ortamı için 4 tekerrür 3 paralelli olarak yürütülmüştür. Bu durumda her bir saksıda 
kontrol dışında diğer sensör tiplerinden üçer adet kullanılmıştır. Sensörlerin örnekleme hacimlerini oluşturan etki alanları, rezistif sensörler için problar arası mesafe kadar ve kapasitif sensörler için dielektrik alanları kadardır. Buna göre, saksı içine dik konumda yerleştirilen sensörler arasında sinyal girişimini engellemek için her bir sensörün etrafında kendi genişliğinin en az iki katı çapta bir boşluk bırakılmıştır. Deneme her bir ortam için 90'ar gün ve her sensör için günde 48 okuma şeklinde sürdürülmüştür.

Toprak nem sensörleri yerleştirildikten sonra her bir yetiştirme ortamındaki tüm saksılar tarla kapasitesi nem düzeyine getirilmiş ve solma noktasına düşünceye kadar yarım saat aralıklarla nem değerleri kaydedilmiştir. Ayrıca her gün sabah ve akşam olmak üzere saksıların ağırıkları tartılarak nem azalımı lizimetrik olarak da takip edilmiştir.

\section{Deneme Sisteminin Tasarımı}

Geliştirilen sistem, Arduino mikroişlemci kontrol kartı temellidir. Bu kart, farklı sensörleri kolayca entegre edebilen ucuz ve yeterli kapasitede bir mikroişlemciye sahiptir. Programlamasının kolaylığı ve birçok üstün özelliklerinden dolayı bu teknoloji seçilmiştir. Birden fazla sensörü barındırabilen, farklı elektronik sistemlerle entegre edilebilen, kendi yazılım platformunu ücretsiz olarak temin eden bu kart dinamik bir teknoloji geliştirme imkânı sağlamaktadır. Çalışmada kullanılan toprak nem sensörleri ve teknik özellikleri Çizelge 1.'de sunulmuştur.

Çizelge 1. Denemede kullanılan toprak nem sensörleri ve teknik özellikleri.

Table 1. Technical specifications of soil moisture sensors.

\begin{tabular}{|c|c|c|}
\hline Sensör modeli & $\begin{array}{c}\text { Teknik özellikler } \\
\end{array}$ & Sensör \\
\hline $\begin{array}{l}\text { Decagon } 10 \mathrm{HS} \\
\text { (Kontrol) }\end{array}$ & $\begin{array}{l}\text { - } 3 \text { - } 15 \text { VDC enerji kullanımı } \\
\text { - }-40 \text { OC ile }+50 \text { OC arası sıcaklıkta çalışabilme } \\
\text { - } \% \pm 3 \text { hassasiyette }\end{array}$ & \\
\hline $\begin{array}{l}\text { Arduino toprak nem sensörü } \\
\text { higrometre } \\
\left(\mathrm{S}_{1}\right)\end{array}$ & $\begin{array}{l}\text { - Potansiyometre ile hassasiyet ayarı } \\
\text { - Çalışma voltajı } 5 \text { VDC } \\
\text { - İki ayrı çıkış: Dijital ve analog } \\
\text { - Küçük PCB boyutu:3cmx } 1.6 \mathrm{~cm} \\
\text { - Güç indikatörü ve anahtarlamalı çıkış indikatörü } \\
\text { - Kararlı LM393 komperatörü }\end{array}$ & \\
\hline $\begin{array}{l}\text { Kapasitif toprak nem sensörü } \\
\left(\mathrm{S}_{2}\right)\end{array}$ & $\begin{array}{l}\text { - Çalışma voltajı: } 3.3 \text { } 5.5 \text { VDC } \\
\text { - Çıkış voltajı: } 0 \sim 3 \text { VDC } \\
\text { - Arayüz: PH2.54-3P } \\
\text { - Boyut: } 98 \text { x 23mm }\end{array}$ & \\
\hline $\begin{array}{l}\text { Gravity analog toprak nem sensörü } \\
\left(\mathrm{S}_{3}\right)\end{array}$ & $\begin{array}{l}\text { - Güç kaynağı: } 3.3 \text { } 5.5 \text { VDC } \\
\text { - Çııış voltaj sinyali: } 0 \text { } 4.2 \text { VDC } \\
\text { - Akım: 35mA } \\
\text { - Analog çıış (Mavi kablo) } \\
\text { - GND (Siyah kablo) } \\
\text { - Güç (Kırmızı tel) } \\
\text { - Boyut: 60x20x5mm } \\
\text { - Yüzey işlemi: Altın Kaplama }\end{array}$ & \\
\hline
\end{tabular}

Kontrol sensöründen alınan yarım saatlik toprak nem değerleri bir veri kaydedicide (Decagon EM-50) depolanmıştır. Diğer sensörlerden her yarım saatte bir alınan veriler ise Arduino tabanlı oluşturulan veri kayıt sistemi aracılığıyla bir hafıza kartında toplanmıştır. Test edilen sensörlerden her okuma zamanı anlık bir veri almak hataya sebebiyet verebileceği için hafıza kartına kaydedilen verilerin $2^{8}$ okumalık hareketli ortalamayla hesaplanması yazılımla sağlanmıştır. Her iki kayıt sisteminin zaman damgaları eşlenerek verilerin her bir sensörden aynı anda alınması sağlanmıştır. Bu şekilde bilgisayara aktarılan veriler tek bir tabloda düzenlenebilmiştir.

Sensörlere gönderilen akımın, eşit şartlarda sinyal oluşturmalarına imkan verecek şekilde düzenlenebilmesini sağlamak için; her biri $110 \mathrm{~cm}$ uzunluğunda, 24 AWG çaplı, çok damarlı teller kullanılmıştır. Her sensör için 1 besleme, 1 negatif ve 1 sinyal kablosundan oluşan demet, sıcak lehim ile yerlerine sabitlenmiştir. Yetiştirme ortamındaki nemin kısa devre oluşturma ihtimaline karşı, açık iletken yüzeyler oluşturan bağlantı noktaları ısıyla daralan makaron ile izole edilmiş ve böylece prototip cihazın üretimine başlanmıştır.

Prototip cihazın beynini oluşturan Arduino mikroişlemci kartı üzerinde analog giriş olarak kullanılabilecek 6 terminal olmasına karşın denemede eşzamanlı veri alınması gereken 40 sensör bulunmaktadır. Sensörlerden 
toplanan verilerin eşit koşullarda alınması, elektronik gürültünün azaltılması için gereklidir. Bu nedenle, tek seferde 40 sensörün bağlanabileceği bir çoklayıcı iç kontrol entegresi oluşturulmuştur. Arduino mikroşlemci kartının 4 dijital çıkış pinine bağlanan iç kontrol entegresi, pinlerin açık-kapalı (high-low) kombinasyonlarına bağlı olarak her seferinde bir sensör verisini okumaktadır. Mikroişlemci önbelleğine analog girişlerden alınan okumalar, sensör setinin tamamı için bir veri sağlandıktan sonra işlem tekrarlanarak sürmektedir.

Sensörlere bağıı analog sinyal kablolarının, çoklayıcı entegre bacaklarıyla bağlantılarının sağlanabilmesi için prototipleme tahtası üzerinde kurulumu yapılmıştır. Sensörlerden alınan verilerin, çoklayıcı entegre üzerinden zamana bağlı olarak Arduino mikroişlemci üniteye aktarılması sağlanmıştır. Üzerinde bir renkli ekran bir de saat entegresi bulunan prototip cihaz, belirlenen aralıklarla verileri hafıza kartında depolamıştır (Şekil 2).

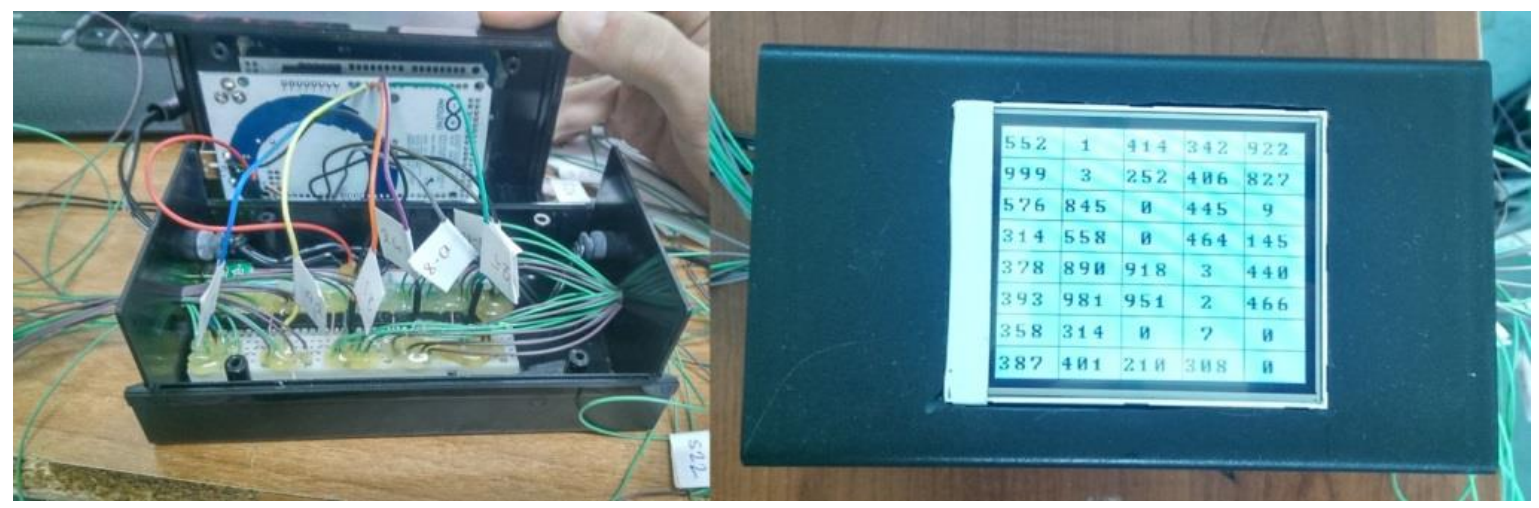

Şekil 2. Deneme sistemi prototipi.

Figure 2. Prototype of the experimental device.

Yetiştirme ortamlarının ilki olan torf ve perlit (1:1) karışımı tartılarak saksılara yerleştirilmiş, ardından sızma başlayana kadar su eklenmiştir. Saksı yüzeyinden buharlaşmayı önlemek için üzerleri kapatılarak 24 saat bekletilmiştir. Tarla kapasitesi seviyesinde nem içeren saksılara sensörler eşit aralıklarla yerleştirilmiş ve kontrol sensörleri ile eşzamanlı olarak kayıt almaya başlatılmışlardır. Prototip cihazın üzerinde sabitlenen renkli ekran sayesinde her bir sensörün tepkisi anlık olarak takip edilmiştir.

\section{Verilerin Analizi}

Tüm sensörlerin kaydedilen verileri MS Excel ortamına aktarılmıştır. Çalışmada, kontrol sensörlerinin lizimetrik olarak kalibrasyonunun gerçekleştirilmesi için regresyon analizinden yararlanılmıştır. Kabul edilebilir belirtme katsayılarının $\left(R^{2}\right)$ elde edilmesinden dolayı analizdeki $n$ sayısını (her yarım saatte bir veri) arttırmak için diğer sensörler ile kontrol sensörü arasında regresyon analizleri yapılmıştır.

\section{BULGULAR VE TARTIŞMA}

\section{Sensörlerle ilgili Teknik Problemler}

Sensör verilerinin kaydedildiği prototip cihazın ekranından anlık olarak takip edilebiliyor olması neticesinde sınır değerlerine ulaşmış bazı sensörlerin arızalandığı tespit edilmiştir.

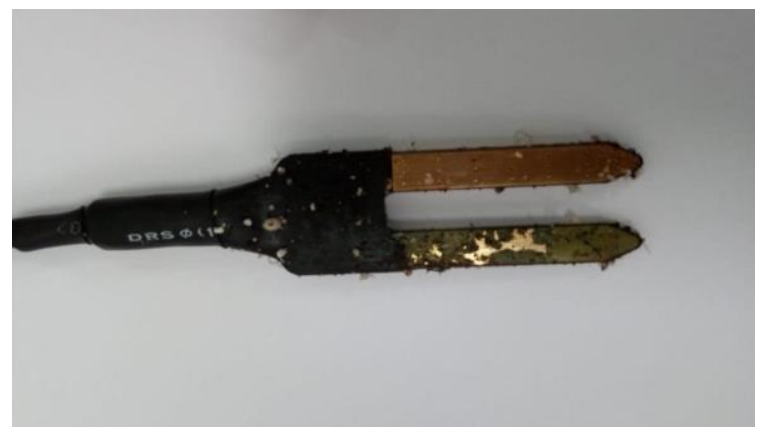

Şekil 3. Oksitlenmiş S3 sensörü.

Figure 3. Oxidized S3 sensor.

Buna göre, topraksız ortam denemesi olan torf-perlit (1:1) karışımında 12. saatte gravity analog toprak nem sensörlerinin tamamen arızalandığı görülmüş ve rastgele bir tanesi yerinden çıkarılarak incelenmiştir (Şekil 3). Sensörün iletken kollarından bir tanesindeki kaplama malzemesinin tamamen oksitlenerek işlevini kaybettiği anlaşılmıştır. 
Benzer şekilde Arduino mikroişlemciyle kaydedilen toprak nem sensörlerinin bazıları 36. saatten itibaren sınır değerlerine ulaşmıştır. Deneme tekerrürünün sonuçlandııılmasının ardından yerlerinden sökülen bu sensörlerde değişen miktarlarda oksitlenme izine rastlanmış olup buna rağmen büyük bir kısmının çalışmaya devam ettiği anlaşılmıştır (Şekil 4).

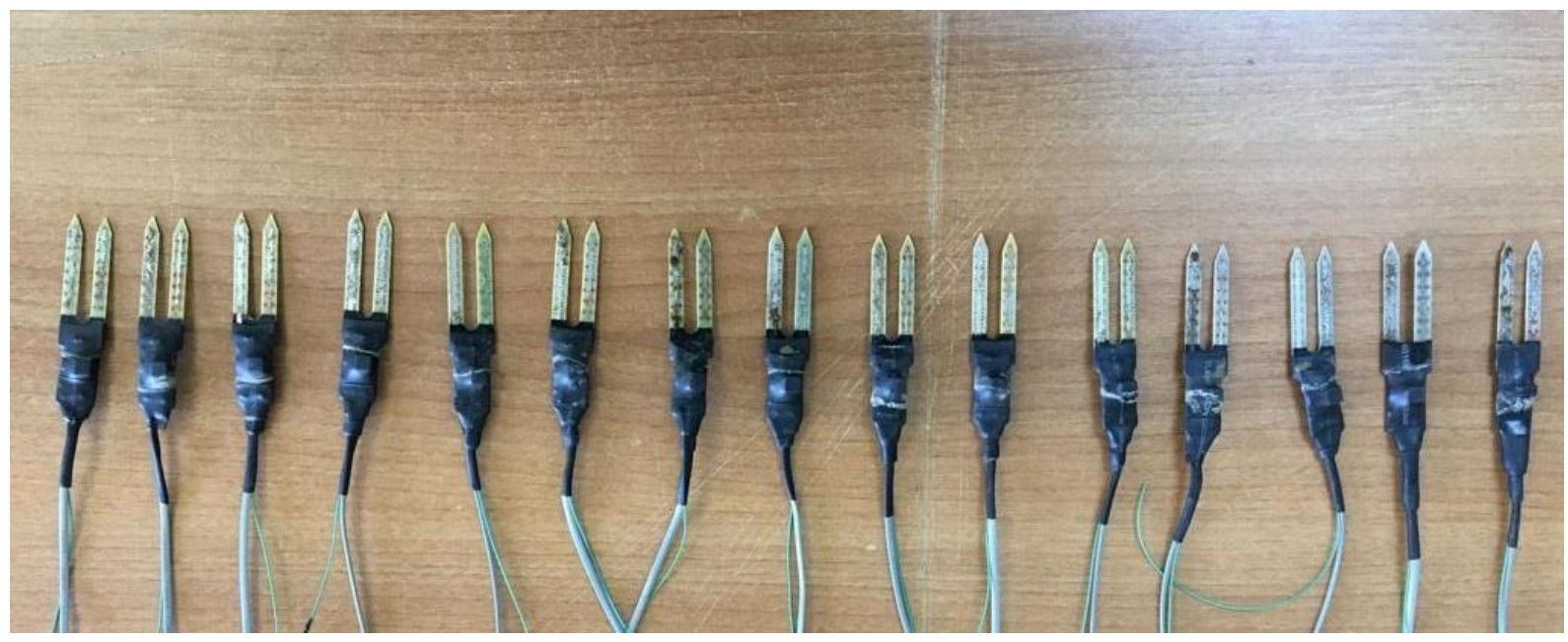

Şekil 4. Birinci test sonunda S1 sensörleri.

Figure 4. 51 sensors at the end of the first test.

Topraksız ortam tekerrürlerinin ardından, sensörlerin hepsi test edilerek arızalı sensörler tespit edilmiş ve yenisi ile değiştirilmiştir. Böylece topraklı ortam denemesi için bütün sensörlerin çalıştığı teyit edilmiştir.

\section{Kontrol Sensörünün Kalibrasyon Hassasiyeti}

Çalışmada kontrol olarak kullanılan sensörlerin referans olarak kullanımının tespiti için lizimetrik prensibe göre kalibrasyon hassasiyetleri belirlenmiş ve elde edilen sonuçlar Şekil 5.'te verilmiştir.

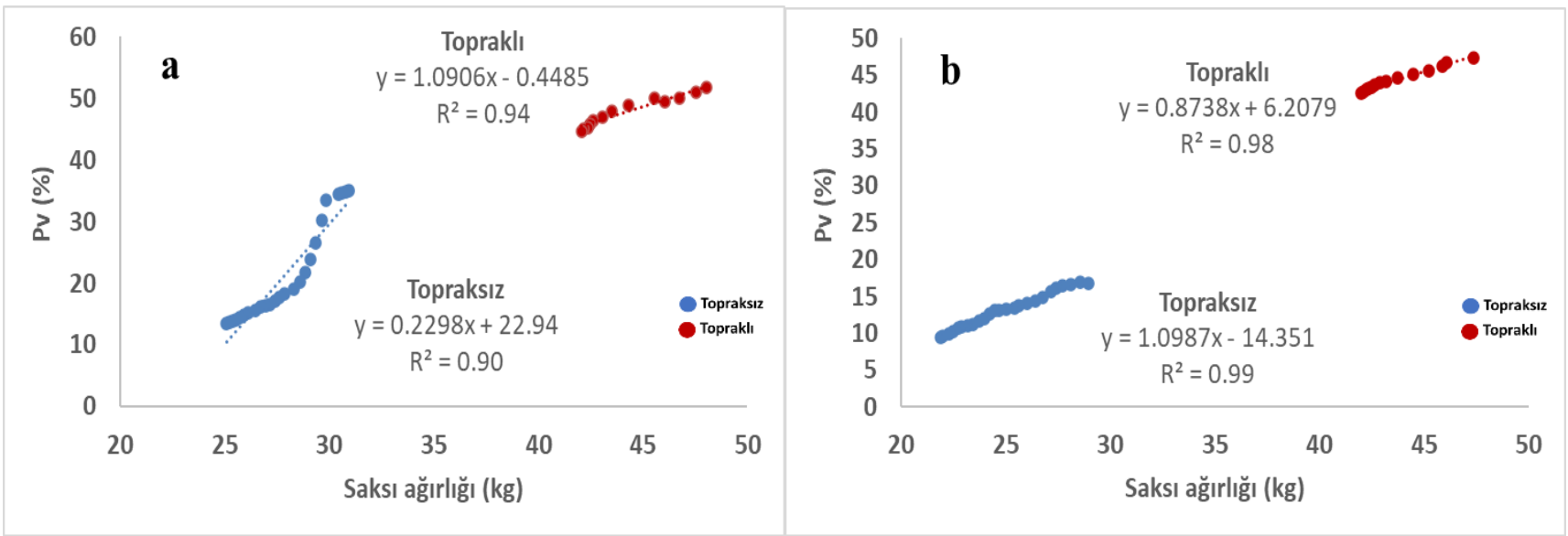

Şekil 5. Kontrol sensörünün birinci (a) ve ikinci (b) testine ilişkin kalibrasyon sonuçları.

Figure 5. Calibration results for the first (a) and second (b) test of the control sensor.

Kontrol sensörlerine ilişkin ortalama $R^{2}$ değerleri, topraklı koşullarda 0.96 ve topraksız koşullarda da 0.95 olarak elde edilmiştir. Söz konusu değerler, toprak neminin bu sensörler ile oldukça yüksek doğrulukla tahmin edilebileceğini göstermiştir. Nitekim daha önceden yapılan çalışmalarda da bu sensörlerin toprak nemini belirlemede başarılı bir şekilde kullanılabileceği bildirilmiştir (Spelman ve ark., 2013; Naglic, 2015; Raper, ve ark., 2015; Lopez Aldaba ve ark., 2018). Bu durum, kontrol sensörlerinin çalışma kapsamında kullanılabilir olduğunu ortaya koymaktadır. 


\section{Kontrol Sensörü ile Arduino Uyumlu Sensörler Arasındaki ilişkiler}

Arduino mikroişlemci ile kullanılan sensörlerin farklı yetiştirme ortamlarında toprak nemine karşı tepkilerini belirlemek için farklı zamanlarda iki kez teste tabi tutulmuş ve kontrol sensörleri ile eş zamanlı veri kaydı sağlanmıştır. Elde edilen bu veriler ile aralarında regresyon analizi yapılmış ve sonuçlar grafiksel olarak göstermiştir. Buna göre, S1 sensörü ile kontrol sensörü arasındaki ilişki incelendiğinde, birinci ve ikinci test sonucunda elde edilen $R^{2}$ değerlerinin ortalamalarına göre topraklı koşullarda $R^{2}=0.75$ ve topraksız koşullarda $R^{2}=0.23$ olarak bulunmuştur (Şekil 6). Ancak, ikinci testte (Şekil 6b) topraklı koşulda elde edilen $R^{2}$ değeri kısmen yüksek gibi gözükse de ilişkinin ters yönde eğilim göstermesi sensörün güvenilirliğini ortadan kaldırmıştır. S2 sensörü için ortalama $R^{2}$ değerleri topraklı ve topraksız koşullara göre sırasıyla 0.61 ve 0.19 olarak elde edilmiştir (Şekil 7). S2 sensörünün birinci testinde pozitif doğrusal ilişki görülürken (Şekil 7a), ikinci teste ters ilişki (Şekil 7b) görülmüştür. Bu durumun ikinci teste geçildiğinde, sistem her ne kadar veri almayı sürdürse de, söz konusu sensörlerin yukarıda açıklandığı şekilde oksitilenerek bozulmasından kaynaklandığı düşünülmektedir. Nitekim S3 sensöründe ikinci teste geçildiğinde belirtilen nedenlerden dolayı hiç veri alınamamıştır. İlk test sonucuna göre elde edilen $\mathrm{R}^{2}$ değerleri, topraklı koşullarda 0.77 , topraksız koşullarda ise 0.39 olarak elde edilmiştir (Şekil 8).
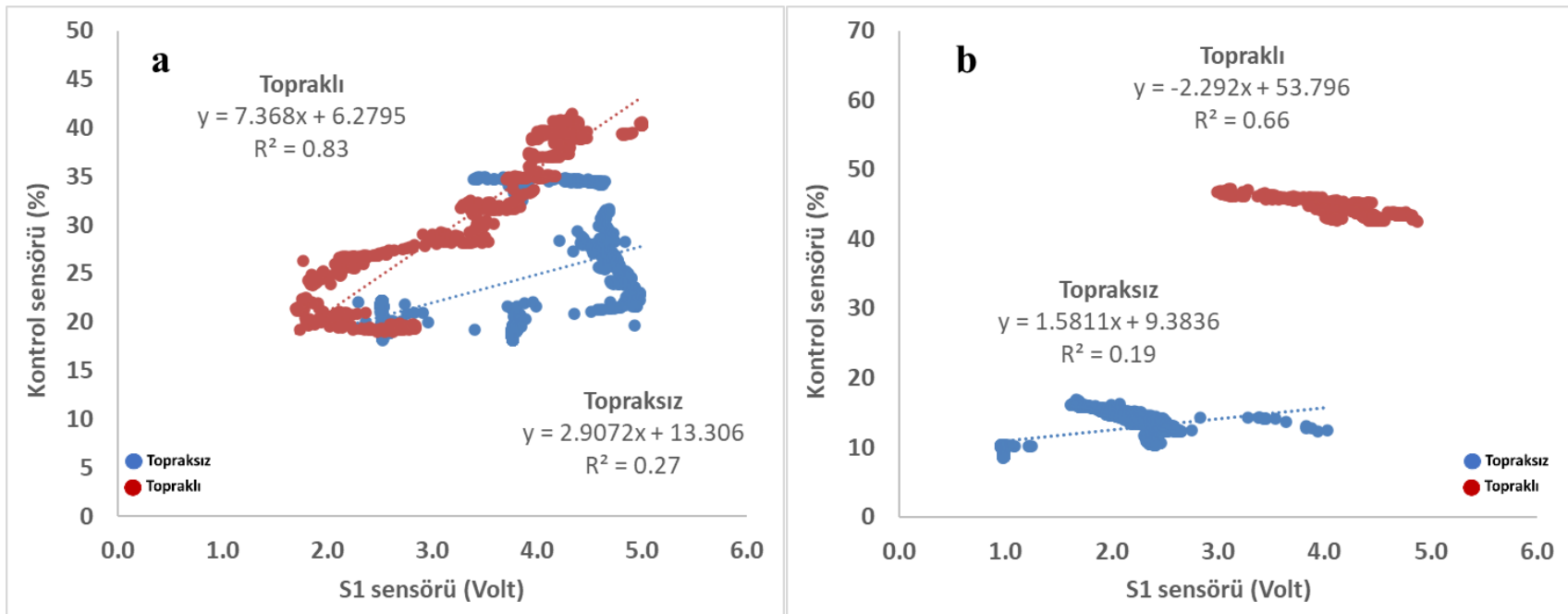

Şekil 6. Birinci (a) ve ikinci (b) test sonuçlarına göre S1 ile kontrol sensörleri arasındaki ilişkiler.

Figure 6. Relationships between $\mathrm{S} 1$ and control sensors according to first (a) and second (b) test results.
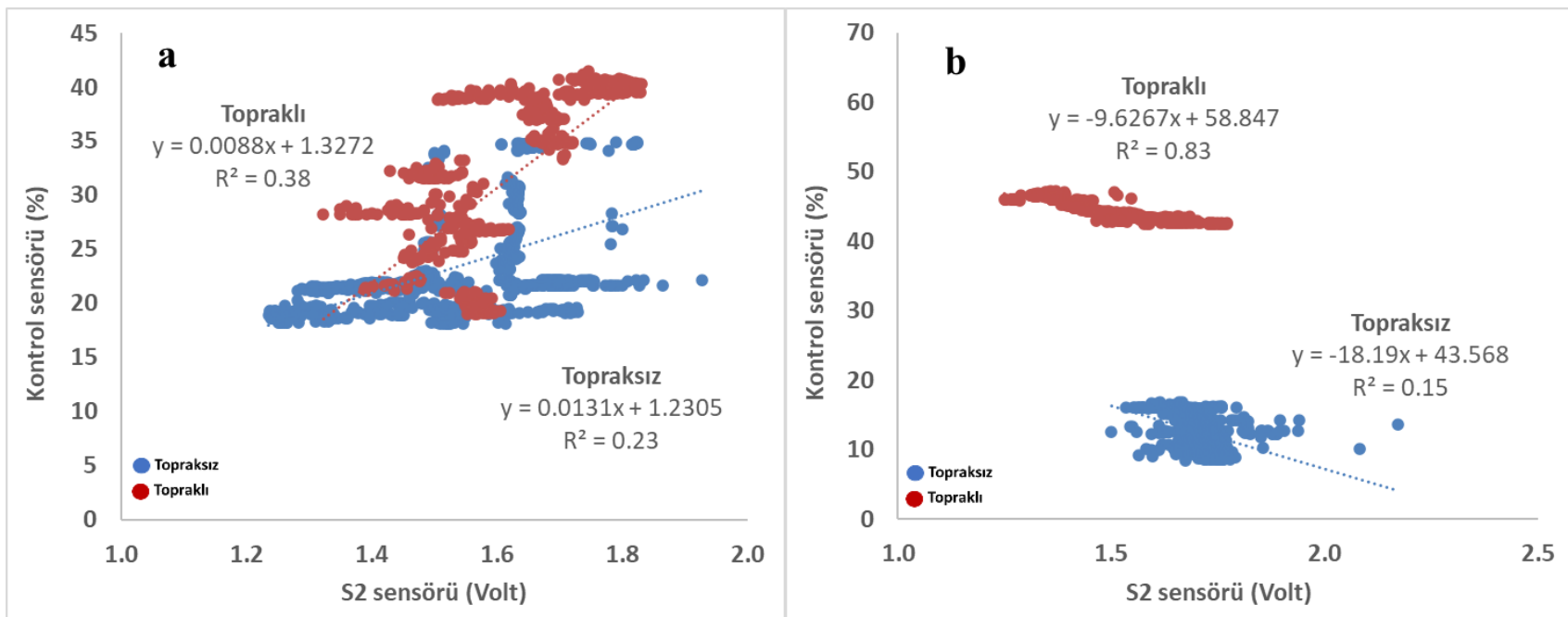

Şekil 7. Birinci (a) ve ikinci (b) test sonuçlarına göre S2 ile kontrol sensörleri arasındaki ilişkiler.

Figure 7. Relationships between S2 and control sensors according to first (a) and second (b) test results. 


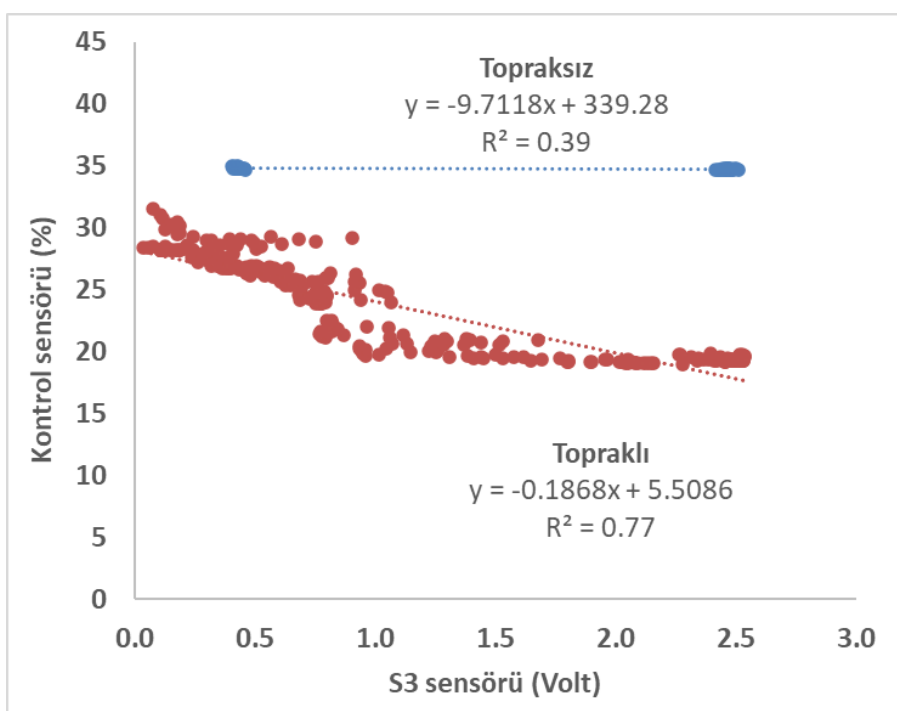

Şekil 8. Birinci test sonucuna göre S3 ile kontrol sensörleri arasındaki ilişkiler.

Figure 8. Relationships between S3 and control sensors according to first test results.

\section{SONUÇ}

Günümüzde bilinen sensörlerin dışında maliyeti oldukça düşük ancak ölçüm doğruluğu ve ömrü henüz tam olarak bilinmeyen sensörler üretilmeye başlanmıştır. Bu bağlamda, düşük maliyetli bu sensörlere ilişkin verilerin ne derece sağlıklı olduğunu ortaya koymak amacıyla yapılan bu çalışmada, kontrol sensörü olarak yaygın şekilde kullanılan ve güvenilirliği ortaya konmuş bir sensörle, 3 farklı toprak nem sensörünün iki farklı yetiştirme ortamında elde edilen sonuçlar ile aralarındaki ilişkilere bakılmıştır. Çalışma sonucunda, her iki ortamda da kontrol sensörünün toprak nemini başarılı bir şekilde belirlediği ortaya konmuştur. Ancak, test edilen ekonomik toprak nem sensörleri topraksız koşullarda bu başarıyı gösterememişlerdir. Bu sensörlerde topraklı koşullarda nemi belirleme kabiliyetinin daha iyi olduğu sonucuna varılmıştır. Kısa süreli ve topraklı koşullar olmak kaydıyla sadece S1 sensörü diğerlerine göre daha başarılı sonuçlar vermiştir. İki ayrı zamanda yapılan testlerde bu sensörlerin düzenli olarak doğru sonuçlar vermediği ve çabuk oksitlenmelerinden dolayı ekonomik ömürlerinin uzun olmadığı gözlemlenmiştir. Deneme düzeninde farklı sensörlerden eş zamanlı veri almak için iç kontrol entegresi kullanılmış olması, sensörlerin üzerinde sürekli besleme olmasını gerektirmektedir. Bununla birlikte, mikroişlemciye doğrudan bağlanan sensörlerin sadece veri alınacağı zaman elektrik yüküne maruz kalmaları sağlanarak oksitlenmenin geciktirilmesi mümkündür. Fakat, kullanılan sensör sayısına bağlı olarak mikroişlemci sayısının artması ve bu mikroişlemcilerin birbirleri ile haberleşme zorunluluğu ise bu şekilde kullanımlarını zorlaştıracaktır. Bu sebeplerden dolayı bu tip sensörlerin kullanılması durumunda, verilerinin sürekli kontrol altında tutulması ve arızalananların yenileriyle değiştirilmeleri sağlanmalıdır.

\section{ÇIKAR ÇATIŞMASI}

Yazarlar olarak makalenin planlanması, yürütülmesi ve yazılması konusunda herhangi bir çıkar çatışması olmadığını beyan ederiz.

\section{YAZAR KATKISI}

Yazarlar olarak makalenin planlanması, yürütülmesi ve yazımı tarafımızca eşit olarak yapılmıştır.

\section{TEŞEKKÜR}

Bu çalışma Çanakkale Onsekiz Mart Üniversitesi, Bilimsel Araştırma Projeleri Koordinasyon Birimi tarafından desteklenmiştir (Proje No: FHD-2018-2610). 


\section{KAYNAKLAR}

Cardenas-Lailhacar, B. C., \& Dukes, M. D. (2010). Precision of soil moisture sensor irrigation controllers under field conditions. Agricultural Water Management, 97, 666-672.

Chow, L., Xing, Z., Rees, H. W., Meng, F., Monteith, J., \& Stevens L. (2009). Field performance of nine soil water content sensors on a sandy loam soil in New Brunswick, Maritime Region, Canada. Sensors, 9, 9398-9413.

Çetin, Ö. (2003). Toprak-Su Ilişkileri ve Toprak Suyu Ölçüm Yöntemleri. Eskişehir Araştırma Enstitüsü Müdürlüğü Yayınları Genel Yayın No: 258, Teknik Yayın No: 25, Eskişehir.

Demirel, K. (2012). Toprak altına serilen su tutma bariyerlerinin (stb) toprak su içeriği ve çim bitkisi gelişimi üzerine etkileri. Doktora Tezi, Çanakkale Onsekiz Mart Üniversitesi, Fen Bilimleri Enstitüsü, Çanakkale.

Heng, L. K., Caycı, G., Kutuk, C., Arrillaga, J. L., \& Moutonnet, P. (2002). Comparison of soil moisture sensors between neutron probe, diviner 2000 and TDR under tomato crops. 17th WCSS, Paper No.1532, Thailand.

Huang, Q., Akinremi, O. O., Sri Rajan, R., \& Bullock, P. (2004). Laboratory and field evaluation of five soil water sensors. Canadian Journal of Soil Science, 84, 431-438.

Leib, B. G., Jabro, J. D., \& Matthews, G. R. (2003). Field evaluation and performance comparison of soil moisture sensors. Soil Science, 168(6), 396-408.

Lopez Aldaba, A., Lopez-Torres, D., Campo-Bescós, M. A., López, J. J., Yerro, D., Elosua, C., Arregui, F. J., Auguste, J.-L., Jamier, R., Roy, P., \& López-Amo, M. (2018). Comparison between capacitive and microstructured optical fiber soil moisture sensors. Applied Science, 8, 1499.

Naglic, B. (2015). Evaluation of a low-cost sensor for soil moisture monitoring. Hop Bulletin, 22 , 66-73.

Paige, G. B., \& Timothy, O. K. (2008). Comparison of field performance of multiple soil moisture sensors in a semi-arid rangeland. Journal of the American Water Resources Association , 44(1), 121-135.

Raper, T. B., Henry, C. G., Espinoza, L., Ismanov, M., \& Oosterhuis, D. M. (2015). Response of two Inexpensive commercially produced soil moisture sensors to changes in water content and soil texture. Agricultural Sciences, 6, 1148-1163.

Spelman, D., Kinzli, K., \& Kunberger, T. (2013). Calibration of the 10hs soil moisture sensor for southwest florida agricultural soils. Journal of Irrigation and Drainage Engineering, 139, 965-971.

Starr, J. L., \& Paltineanu, I. C. (1998). Real-time soil water dynamics over large areas using multisensor capacitance probes and monitoring system. Soil\&Tillage Research, 47, 43-49.

Topp, G. C. (2003). State of the art measuring soil water content. Hydrological Process, 17, 2993-2996. 